\title{
Reseñas
}

SEIS LECCIONES DE DIBUJO

Wiliam Kentridge (2018). Buenos Aires,

El Hilo de Ariadna, 272 págs.

William Kentridge

\section{Seis lecciones de dibujo}

Treabucción bo Cisubia Masst

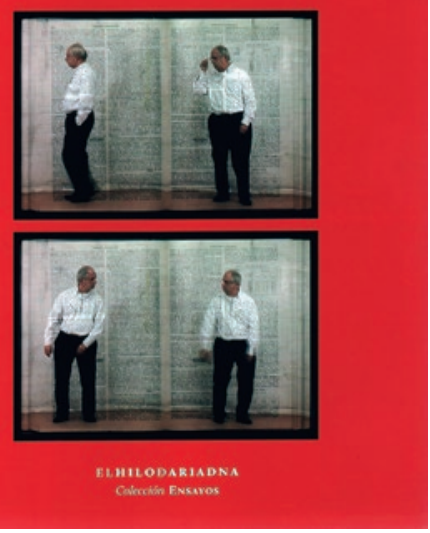

Janitzio Alatriste Tobilla

Universidad Autónoma del Estado de México

janitziobyn@gmail.com

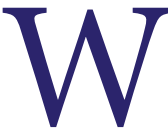

illiam Kentridge es un artista que se encuentra en su sexta década de vida, de origen sudafricano blanco, lo podríamos contextualizar como productor de arte contemporáneo en el sentido de que su obra no responde a las convenciones asimiladas en la cultura global como arte, sino al quebrantamiento de éstas. Su producción de forma muy general se podría caracterizar como dibujo, pero siempre proponiendo desplazamientos de este hacia el performance, la animación, el cine, la ópera y la escultura.

La reciente edición que ha llegado a nuestro país, con el texto de las seis conferencias que William Kentridge impartió 
en la Universidad de Harvard en 2012, resulta reveladora por diversas causas, la más trascendente, en mi comprensión, es que poco se habla de dibujo.

Kentridge decidió llamar a su libro Seis "lecciones" de "dibujo", sin embargo no trata de lo que se entiende convencionalmente por dibujo, y aun menos sobre la enseñanza de este; lo que encontramos ahí son ideas, fascinaciones, obsesiones, acciones, etc., pero muy ocasionalmente algún dibujo, y más bien la referencia a alguno de sus desplazamientos hacia una ópera, una acción o una máquina que distorsiona la imagen.

¿Será que Kentridge sí nos habla de dibujo? Pero, ¿quizá no es evidente? En la organización de estas conferencias se plantea un orden, y sucesivamente aborda: el mito de la caverna de Platón, revaluando las sombras como la realidad; las revueltas coloniales en contra del racismo en Sudafrica con toda la brutalidad que marcó su infancia; la historia de su ciudad natal, Johanesburgo, como una ciudad surgida de lo subterráneo que se ha empeñado en mantenerlo a este invisible; la organización de su estudio de producción, que nunca es un espacio determinado, pero sí, siempre, un lugar; sus procesos de apropiación, entendidos como traducciones que llevan al malentendido y este como fuente de incertidumbre cognitiva, y finalmente; el tiempo, en clave de entropía, o lo que él sugiere: "antientropía", que siempre produce un retorno imposible, pero esa esperanza nos mantiene activos.

Es decir, nada de proporciones, ni perspectivas, mímesis, ni observación de modelo, ni claroscuros, ni semejanzas, ni "dibujar las cosas como son”. Entonces, o William Kentridge no nos habla de dibujo o el dibujo no es lo que hemos creído hasta hoy. Aún no lo sé, quizá haya que leerlo y entre muchos platicarlo. 